\title{
Screening method for Staphylococcus aureus identification in subclinical bovine mastitis from dairy farms
}

\author{
Natapol Pumipuntu ${ }^{1}$, Suphang Kulpeanprasit ${ }^{1}$, Sirijan Santajit ${ }^{1}$, Witawat Tunyong ${ }^{1}$, Thida Kong-ngoen ${ }^{1}$, \\ Woranich Hinthong ${ }^{2}$ and Nitaya Indrawattana ${ }^{1}$
}

1. Department of Microbiology and Immunology, Faculty of Tropical Medicine, Mahidol University, Bangkok, Thailand; 2. Faculty of Medicine and Allied Health, HRH Princess Chulabhorn College of Medical Science Bangkok, Thailand. Corresponding author: Nitaya Indrawattana, e-mail: nitaya.ind@mahidol.ac.th

Co-authors: NP: film.natapol@gmail.com, SK: Suphang.kpt@gmail.com, SS: sirijan.santajit@gmail.com, WT: witawat.tun@mahidol.ac.th,TK: thida.kon@mahidol.ac.th,WH: p_prem85@yahoo.com Received: 09-02-2017, Accepted: 12-05-2017, Published online: 01-07-2017

doi: 10.14202/vetworld.2017.721-726 How to cite this article: Pumipuntu N, Kulpeanprasit S, Santajit S, Tunyong W, Kong-ngoen T, Hinthong W, Indrawattana N (2017) Screening method for Staphylococcus aureus identification in subclinical bovine mastitis from dairy farms, Veterinary World, 10(7):721-726.

\begin{abstract}
Background: Staphylococcus aureus is one of the most important contagious bacteria causing subclinical bovine mastitis. This bacterial infection is commonly identified by determine the pathogen in bovine milk samples through conventional technique including coagulase test. However, this test has several disadvantages as low sensitivity, risk of biohazard, cost expensive, and limited preparation especially in local area.
\end{abstract}

Aim: Aim of this study was to compare and assess the screening method, Mannitol fermentation test (Mannitol salt agar [MSA]), and deoxyribonuclease (DNase) test, for $S$. aureus identification in milk samples.

Materials and Methods: A total of 224 subclinical bovine mastitis milk samples were collected from four provinces of Thailand and determined $S$. aureus using conventional method and also subjected to the screening test, MSA and DNase test. The sensitivity, specificity, positive predictive value (PPV), and negative predictive value (NPV) among both tests were analyzed and compared to the tube coagulase test (TCT), as reference method. Immunological test by latex agglutination and molecular assay by determined spa gene were also used to identify and differentiate $S$. aureus.

Results: A total of 130 staphylococci were isolated by selective media, Gram-stain, and catalase test. The number of S. aureus which identified using TCT, MSA and DNase test were 32, 102, and 74 isolates, respectively. All TCT results were correlated to results of latex agglutination and spa gene which were $32 \mathrm{~S}$. aureus. MSA showed $100 \%$ sensitivity, 28.57\% specificity, 31.37\% PPV, and 100\% NPV, whereas DNase showed 53.13\% sensitivity, 41.84\% specificity, 22.97\% PPV, and $73.21 \%$ NPV. DNase test showed higher specificity value than MSA but the test presented $26.79 \%$ false negative results whereas no false-negative result from MSA when comparing to TCT.

Conclusion: MSA had a tendency to be a good preference for screening $S$. aureus because of its high sensitivity and NPV. The result from this study will improve a choice to use a screening test to diagnose $S$. aureus of veterinary field for prompt disease controlling and effective treatment.

Keywords: bovine mastitis, deoxyribonuclease test, mannitol fermentation test, screening methods, Staphylococcus aureus.

\section{Introduction}

Bovine mastitis is a disease of the most prevalence and costly diseases in dairy cows or some livestock milk industries with losses lead to reducing of milk production, changing in milk composition, discarding or low quality milk, increasing veterinary services, and increasing labor costs [1]. This inflammation of the mammary gland can be divided into two types that manifested by the appearance of inflammation at the udder of dairy cow; asymptomatic (subclinical mastitis) and symptomatic mastitis (clinical mastitis), whereas subclinical mastitis

Copyright: Pumipuntu, et al. Open Access. This article is distributed under the terms of the Creative Commons Attribution 4.0 International License (http://creativecommons.org/licenses/ by/4.0/), which permits unrestricted use, distribution, and reproduction in any medium, provided you give appropriate credit to the original author(s) and the source, provide a link to the Creative Commons license, and indicate if changes were made. The Creative Commons Public Domain Dedication waiver (http:// creativecommons.org/publicdomain/zero/1.0/) applies to the data made available in this article, unless otherwise stated. can be occurred up to 40 times more common than clinical cases [2]. Thus, this subclinical mastitis seems to be an important type of mastitis in dairy cow because it is a hidden mastitis or invisible problem in the herd [3] and needed to be more concern. Staphylococcus species are one of the main etiological bacteria that cause bovine mastitis especially for Staphylococcus aureus which is considered as a contagious pathogen that often cause bovine mastitis [4]. These bacteria can spread from infected cow to another cow in a herd by mainly through many routes as contaminated milking equipment or through hands of farmers. $S$. aureus infection in subclinical bovine mastitis becomes to be a large and important problem in dairy farm industry [5]. There are estimates that about $80-100 \%$ of all dairy herds have at least some $S$. aureus mastitis, with from $5 \%$ to $10 \%$ of infected cows [6]. In Thailand, the prevalence of $S$. aureus infection in dairy cattle subclinical mastitis is also different in each study site such as $8 \%$ and $3 \%$ 
of the bacterial isolates in Chiang Mai [7] and Khon Kaen [8], respectively.

Conventional method is the gold standard for identification of staphylococcal infection from the clinical specimen. Tube coagulase test (TCT) is the one of biochemical tests that commonly used to differentiate $S$. aureus from coagulase-negative staphylococci for a reason that the bacteria can produce coagulase protein to promote coagulation [9-12]. This protein enzyme can activate the nonproteolytic activation of prothrombin and cleavage of fibrinogen [13]. In routine laboratory, TCT is normally prepared from plasma of human or rabbit or horse [14]. Nevertheless, the differentiation of $S$. aureus by TCT spent a times to monitor and interpret the results [15]. Moreover, the interpretation of TCT needs the expertise to clarify the results [16]. Risk of biohazard from TCT can be happen when the plasma derived from the infectious plasma whatever from human or animal [17]. Furthermore, some $S$. aureus may produce low amount of coagulase which render false negative result in TCT [18].

Beside the disadvantage of TCT, Mannitol salt agar (MSA) and deoxyribonuclease (DNase) testing are the other biochemical methods which can be used for screening the differentiation of $S$. aureus from other species. Due to $S$. aureus can ferment mannitol sugar and produces an acid at the end product when inoculated on MSA result in the phenol red indicator change the color from red to yellow [19]. Since $S$. aureus has an ability to produce enzyme DNase which can hydrolyze nucleic acid in DNase medium agar, then it will be seen a clear zone around bacterial colonies [20]. From the limitation in some laboratories which in short supply to find some plasma to perform the coagulase test by the reason of its expensive and risk of biohazard that we mentioned above. MSA and DNase are interested to use instead of TCT [21]. Therefore, this study aims to evaluate the efficiency of MSA and DNase for screening S. aureus in milks of subclinical bovine mastitis cases from four provinces in Thailand comparing to TCT. The sensitivity, specificity, positive predictive value (PPV), and negative predictive value (NPV) were determined. The result from this study will provide a choice of a screening test for diagnose $S$. aureus of veterinary field for further prompt disease controlling and effective treatment.

\section{Materials and Methods}

\section{Ethical approval}

All procedures performed in this study were approved by the Faculty of Tropical Medicine-Animal Care and Use Committee, Mahidol University, Thailand (protocol no. 002-2016).

\section{Sample collection and preparation}

Individual 224 milk samples were aseptically collected from subclinical bovine mastitis cases in from 52 dairy farms which 8 different areas Thailand, i.e.; Saraburi, Lopburi, Nakorn Ratchasima, and Maha
Sarakham provinces during September 2015 to April 2016. All samples were inoculated on Columbia blood agar supplemented with nalidixic acid and colistin sulfate for Staphylococcus spp. and Streptococcus spp. (Oxoid, Hampshire, UK) and incubated at $35^{\circ} \mathrm{C}$ for $18 \mathrm{~h}$. The suspected bacterial colonies were subjected to conventional methods such as Gram-stain, catalase test, coagulase test, MSA, and DNase.

\section{Screening test for $S$. aureus}

Staphylococcal isolates which showed positive result for catalase test were subcultured on human blood agar and incubated at $37^{\circ} \mathrm{C}$ for $24 \mathrm{~h}$. Then, the single colonies were subjected to the screening test, i.e., MSA, DNase and TCT, respectively.

\section{MSA}

MSA contains $1 \%$ mannitol, $7.5 \%$ sodium chloride, phenol red indicator, and peptone. S. aureus can tolerate and survive in high salt condition in this medium and can grow on it whereas the other bacteria will be inhibited by the high salt concentration from the media. S. aureus can ferment the sugar mannitol and from this ability it produces an acid at the end product that changes phenol red indicator into yellow. In this experiment, the suspected single bacterial colony was inoculated on MSA plate (Oxoid, Basingstoke, UK), incubated at $35^{\circ} \mathrm{C}$ for $24 \mathrm{~h}$ and observed the indicator change (Figure-1).

\section{DNase test}

DNase agar contains $2 \%$ tryptose, $0.2 \%$ deoxyribonucleic acid, $0.5 \%$ sodium chloride, and methyl green indicator. $S$. aureus has ability to produce enzyme DNase which can hydrolyze nucleic acid in DNase medium and was seen a colorless zone around their colonies. In this study, the single bacterial colony was inoculated on DNase plate (Oxoid, Basingstoke, UK), incubated at $37^{\circ} \mathrm{C}$ for $18 \mathrm{~h}$ and observed the colorless zone around bacterial colony which indicated the colony of $S$. aureus (Figure-1).

\section{TCT}

TCT is prepared using human or animal plasma. The test aspired for detecting free coagulase of $S$. aureus. Free coagulase is secreted from extracellular specifically by $S$. aureus that reacted with the coagulase reacting factor in plasma that able to from a complex together, which called thrombin. The thrombin has ability to convert fibrinogen to fibrin resulting in clotting of plasma. This thrombin can be called staphylothrombin. In this study, TCT was done by adapted the protocol from Murray, 2003 [22]. The full loop of fresh suspected colonies with $1 \mathrm{ml}$ of human plasma, then incubated the mixture at $37^{\circ} \mathrm{C}$ and observed for clotting formation by gently tilting it horizontal from the vertical after incubated for 4, 6 and $24 \mathrm{~h}$. Plasma clotting was considered to be a positive result for coagulase test (Figure-1).

All methods have subjected with $S$. aureus ATCC 25923 as positive control and Staphylococcus 
epidermidis ATCC 12228 was used as a negative control, respectively.

\section{Verify assays for differentiate $\boldsymbol{S}$. aureus}

\section{Latex agglutination}

The suspected bacterial isolates, which showed gram positive cocci and positive for catalase test, were determined to be $S$. aureus by Staphaurex Plus kit (Remel Europe Ltd., Dartford, UK) based on immuno-agglutination technique. The latex particle was coated with rabbit immunoglobulin $\mathrm{G}$ ( $\mathrm{IgG}$ ) and fibrinogen which can render the interaction of fibrinogen and $S$. aureus clumping factor, the Fc portion of IgG and $S$. aureus protein A and specific IgG and $S$. aureus cell surface antigens. The experiment was done following to the manufacture's protocol [23]. Two drops of bacterial suspension was mixed with a drop of latex particle reagent on a reaction card. Then, the card was rotated smoothly for 30 seconds before observing noticeable agglutination. $S$. aureus strain ATCC 25923 was used as positive control which showed the mixture agglutination whereas no agglutination when tested with $S$. epidermidis strain ATCC 12228, a negative control. The staphaureux-positive isolates were determined the spa gene by polymerase chain reaction (PCR).

\section{Amplification of spa gene}

Several studies used the molecularmethod to determine $S$. aureus by amplify the spa gene that is encoded for protein A [24,25]. Bacterial genomic DNA was extracted using DNA extraction kit (Geneaid, Taiwan). The PCR mixture $(25 \mu \mathrm{L})$ consisted of $1 \mu \mathrm{M}$ of forward primer (5'-CAAGCACCAAAAGAGGAA-3') and reverse primer (5'-CACCAGGTTTAACGACAT-3'), $100 \mathrm{ng}$ of DNA template, $2.5 \mu \mathrm{L}$ of $10 \times$ Taq PCR buffer, $0.2 \mathrm{mM}$ dNTP, $2 \mathrm{mM} \mathrm{MgCl}$, and 1 unit of Taq DNA polymerase (Thermo Scientific, USA). The PCR mixture was subjected to the following thermal cycle conditions using the $\mathrm{T} 100^{\mathrm{TM}}$ Thermal Cycler (BioRad, USA): 95 min of $95^{\circ} \mathrm{C}$ before 35 cycles of amplification at $95^{\circ} \mathrm{C}$ for $45 \mathrm{~s}, 58^{\circ} \mathrm{C}$ for $45 \mathrm{~s}$, and $72^{\circ} \mathrm{C}$ for $45 \mathrm{~s}$, followed by a final extension at $72^{\circ} \mathrm{C}$ for $10 \mathrm{~min}$. The PCR products were analyzed by $1.5 \%$ agarose gel electrophoresis and ethidium bromide staining [26]. The DNA bands, size 300 base pairs (Figure-2), were observed under a Gel Doc ${ }^{\mathrm{TM}} \mathrm{XR}+$ System (Biorad, USA). S. aureus ATCC 25923 and S. epidermidis ATCC 12228 were used in this study as positive and negative control, respectively.

\section{Efficiency analysis}

The SPSS software (version 20.0) was used for statistical analysis. The sensitivity and specificity of MSA and DNase were analyzed using two $\times$ two tables as the followings formulas:

Sensitivity $(\%)=\frac{\text { True positive }}{\text { All positive }} \times 100$
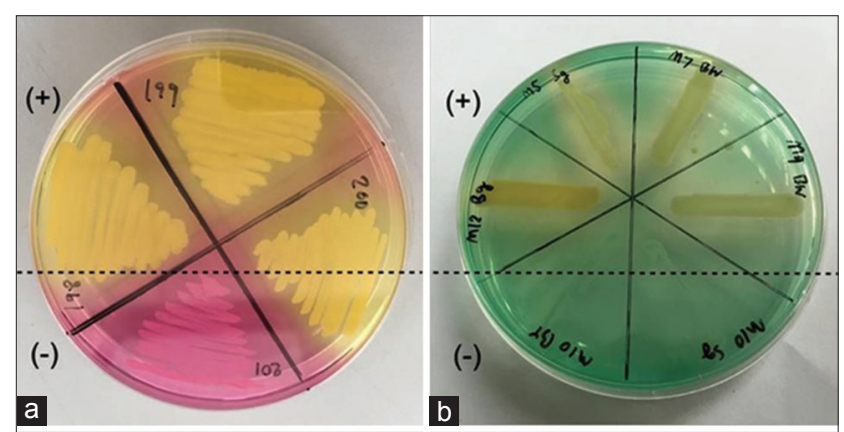

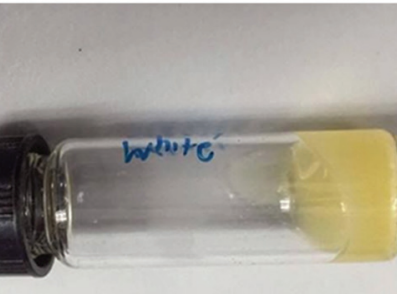

$(+)$

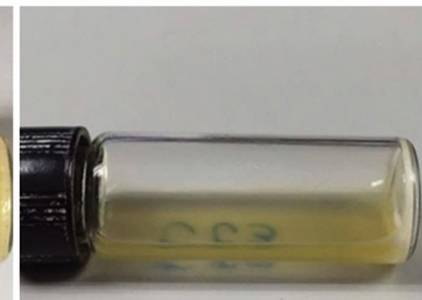

$(-)$ c

Figure-1: Screening tests for identification of Staphylococcus aureus from subclinical bovine mastitis milk sample. (a) Mannital salt agar; (b) deoxyribonuclease test and (c) tube coagulase test. $(+)$ - positive result; $(-)$ - negative result.

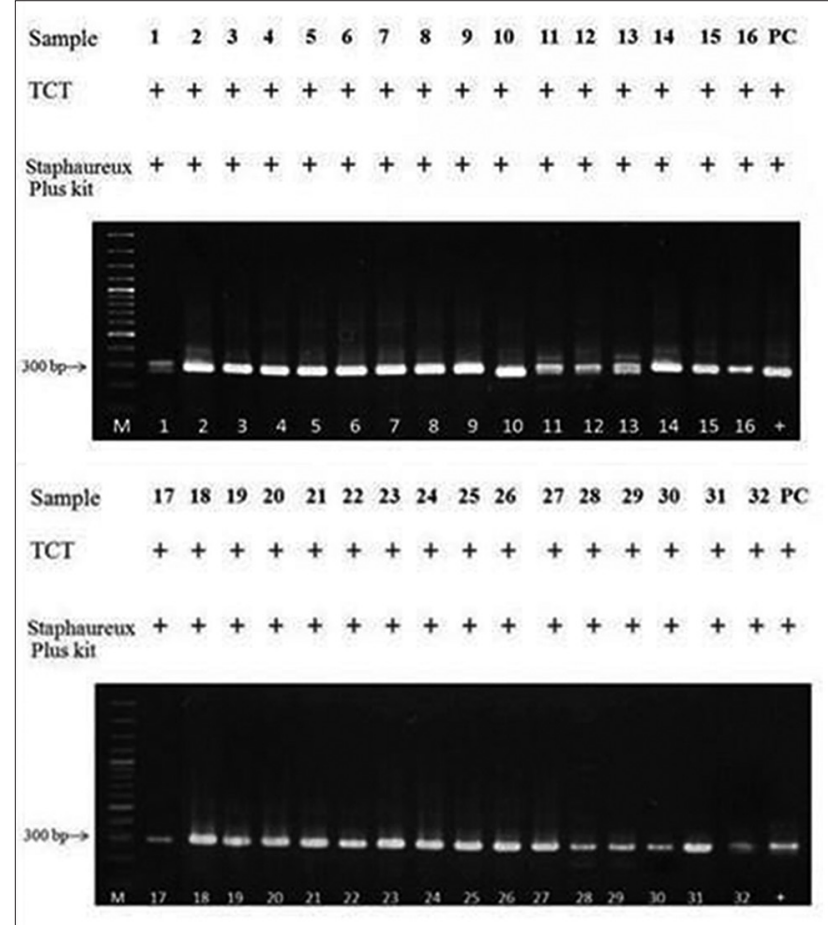

Figure-2: Staphylococcus aureus identification by using tube coagulase test, Staphareux Plus kit and spa gene amplification. Lane M, 100 bp DNA ladder; Lane 1-32, Staphylococal isolate DNA samples; Lane PC, S. aureus ATCC 25923 (positive control). Spa amplicon is $300 \mathrm{bp} .(+)$ - positive result.

Specificity $(\%)=\frac{\text { True negative }}{\text { All negative }} \times 100$

Positive predictive value $(\mathrm{PPV})(\%)=\frac{\text { True positive }}{\text { True positive }+} \times 100$

False positive 
Negative predictive value $(\mathrm{NPV})(\%)=\frac{\text { True negative }}{\text { True negative }+} \times 100$
False negative

\section{Results}

From total 224 milk samples, 130 Staphylococcus spp. were isolated by the selective media (Columbia supplemented with the inhibitors), Gram-stain and catalase test. As showed in Table1 , there were $78.46 \%$ (102/130), 56.92\% (74/130), and $24.65 \%(32 / 130)$ staphylococcal isolates showed positive result on MSA test, DNase test and TCT test, respectively. All 32-positive TCT isolates were also positive for both Staphaureux Plus and spa gene as showed in Figure-2.

The efficiency of MSA showed 100\% sensitivity, 28.57\% specificity, 31.37\% PPV, and 100\% NPV. Whereas, the efficiency of DNase showed $53.13 \%$ sensitivity, 41.84\% specificity, 22.97\% PPV, and 73.21\% NPV (Table-2). DNase test showed higher specificity value than MSA but the test presented 26.79\% (15/56) false negative results whereas no false-negative result from MSA when comparing to TCT. The efficiency of the combination tests, MSA and DNase, for screening $S$. aureus also determined (Table-2.). The combined test presented $100 \%$ sensitivity, $17.39 \%$ specificity, $30.9 \% \mathrm{PPV}$, and 100\% NPV.

\section{Discussion}

Screening method for identification of $S$. aureus is important and necessary for prevention and control in dairy herd for veterinary field and animal health. There has less report about the evaluation of

Table-1: Screening for Staphylococcus aureus from subclinical bovine mastitis milk sample by MSA and DNase test comparing to tube coagulase test.

\begin{tabular}{lccc}
\hline Biochemical test & $\begin{array}{c}\text { Number } \\
\text { isolates }\end{array}$ & \multicolumn{2}{c}{ Tube coagulase test } \\
\cline { 3 - 4 } & $(\mathbf{n})$ & Positive (n) & Negative (n) \\
\hline MSA (+) & 102 & 32 & 70 \\
MSA (-) & 28 & 0 & 28 \\
DNase (+) & 74 & 17 & 57 \\
DNase (-) & 56 & 15 & 41 \\
MSA, DNase $(+,+)$ & 55 & 17 & 38 \\
MSA, DNase $(+,-)$ & 47 & 16 & 31 \\
MSA, DNase $(-,+)$ & 20 & 0 & 20 \\
MSA, DNase $(-,-)$ & 8 & 0 & 8 \\
\hline
\end{tabular}

Total 130 Staphylococcal isolates. MSA=Mannitol salt agar, DNase $=$ Deoxyribonuclease test screening method for this pathogen especially with clinical sample from animal. Our study demonstrates that MSA show high sensitivity and can be used as screening test for differentiates $S$. aureus from animal specimen which possible infected with various species of Staphylococcus. The results similar to other reported from Kateete et al. [27] which screening clinical staphylococcal isolates from human by using MSA and combination method (MSA/ DNase). They reported that MSA had higher sensitivity and NPV but lower specificity and PPV than DNase test. They also concluded that a combination of MSA and DNase which had highest sensitivity was the best choice for screening and identifying of S. aureus clinical isolates [27]. However, our study showed similar sensitivity value $(100 \%)$ of MSA and the combination method (MSA and DNase test). Moreover, screening S. aureus from Staphylococcus isolates using MSA method showed higher specificity than the combination test. Consequently, MSA would be the best choice to screen and identify $S$. aureus isolated from bovine mastitis milk rather than the combined method even the PPV is very close $(31.4 \%$ vs. $30.9 \%)$. While DNase test, presented low sensitivity and specificity, may not appropriate to use for screening and identifying as a single test. Furthermore, MSA had 100\% NPV, it means that negative-MSA result can reliable as true negative result. MSA is appropriate to rule out the negative result as non- $S$. aureus isolates. Besides, many studies reported that DNase test showed lower sensitivity than MSA when compare the results with TCT $[17,27,28]$. Although DNase test showed higher sensitivity value than TCT, it may not suitable to use for screening $S$. aureus infection in dairy cows. Because of the DNase test showed high false negative results which render the infected cow (false negative-DNase test) will not treat and still be with the uninfected animal. Thus, the mastitis infection can disseminate in the dairy farm via this management. Therefore, it is extremely important to choose the appropriate screening test with provide the true negative result for quarantine $S$. aureus infected animal out from uninfected animal in order to medicate, prevent and limit the exposure and expansion of the infection in farms.

Furthermore, if we compared MSA, DNase and TCT in the terms of economic or cost of commercial media, they were found that MSA was very low priced. It was cheaper than DNase test 1.5 times and cheaper

Table-2: The calculated efficiency of MSA and DNase tests for screening of Staphylococcus aureus from subclinical bovine mastitis milk sample.

\begin{tabular}{lcccc}
\hline Biochemical tests & Sensitivity (\%) & Specificity (\%) & PPV (\%) & NPV (\%) \\
\hline MSA & 100 & 28.57 & 31.37 & 100 \\
DNase & 53.13 & 41.84 & 22.97 & 73.21 \\
MSA and DNase* & 100 & 19.15 & 30.9 & 100 \\
\hline
\end{tabular}

*Only MSA, DNase $(+,+)$ and MSA, DNase $(-,-)$ were considered for this calculation. MSA=Mannitol salt agar, DNase $=$ Deoxyribonuclease test, $P P V=$ Positive predictive value, NPV=Negative predictive value 
than TCT about 50 times. Therefore, MSA is a good choice to be an optimal choice for initial screening of $S$. aureus infection in dairy herd.

\section{Conclusion}

The use of MSA seems to be a valuable tool for initial screening and identifying of $S$. aureus clinical isolates in bovine milk sample. It can be used to screen $S$. aureus infection in local laboratories nearby agricultural fields in order to assist veterinarians for diagnosing and making a decision to readily medicate, control and prevention. However, if veterinarians suggest culling the infected cows out of the farm as $S$. aureus infection after MSA positive result, they need to be confirmed this bacterial infection by TCT or other molecular techniques before culling.

\section{Authors' Contributions}

NP and NI planed and designed of the study. The samples were collected in the fields by NP. Laboratory works were done by NP, SK, SS, WT, TK and WH. NI and NP analyzed the data and achieved statistical analysis. NP drafted and revised the manuscript under the advice from NI. Finally, all authors read and approved the final manuscript.

\section{Acknowledgments}

The work was supported by NSTDA Chair professor grant (P-1450624) funded by the Crown Property Bureau of Thailand and RSA5980048 of the Thailand Research Fund (TRF). Thanks are due to Professor Wanpen Chaicumpa, Center of Research Excellence on Therapeutic Proteins and Antibody Engineering, Department of Parasitology, Faculty of Medicine Siriraj Hospital, Mahidol University, Thailand, for her valuable advised and Satitpong Promsatit, DVM, Saraburi Provincial Livestock Office, Department of Livestock Development, Ministry of Agriculture and Cooperatives, Saraburi, Thailand, for his cooperation in the field.

\section{Competing Interests}

The authors declare that there is no conflict of interest in this research.

\section{References}

1. Hillerton, J.E. and Berry, E.A. (2005) Treating mastitis in the cow-a tradition or an archaism. J. Appl. Microbiol., 98(6): 1250-1255.

2. Islam, M.R., Ahamed, M.S., Alam, M.S., Rahman, M.M., Sultana, T., Roh, Y.S. and Kim, B. (2011) Identification and antibiotic sensitivity of the causative organisms of sub-clinical mastitis in sheep and goats. Pak. Vet. J., 32(2): 179-182.

3. Yadav, S., Sharma, M., Yadav, A. and Chaudhary, U.A. (2014) Study of biofilm production in Staphylococcus aureus. Int. J. Pharm. Biol. Sci., 3(2): 61-63.

4. National Mastitis Council. (1996) Current Concepts of Bovine Mastitis. $4^{\text {th }}$ ed. National Mastitis Council, Arlington, VA.

5. Plozza, K., Lievaart, J.J., Potts, G. and Barkema, H.W.
(2011) Subclinical mastitis and associated risk factors on dairy farms in New South Wales. Aust. Vet. J., 89(1-2): 41-46.

6. Jürgen, S., Bärbel, K., Wilfried, W., Michael, Z., Axel, S. and Klaus, F. (2003) The epidemiology of Staphylococcus aureus infections from subclinical mastitis in dairy cows during a control programme. Vet. Microbiol., 96(1): 91-102.

7. Witaya, S. (2011) Epidemiology of subclinical mastitis and their antibacterial susceptibility in smallholder dairy farms, Chiang Mai province, Thailand. J. Anim. Vet. Adv., 10(3): 316-321.

8. Jaruwan, K., Varaporn, S., Anantachai C., Sarinya, R. and Arunee, P. (2010) Chronic mastitis in small dairy cattle herds in Muang Khon Kaen. Thai J. Vet. Med., 40(3): 265-272.

9. Balows, A., Hausler, W.J., Hermann, K.L., Isenberg, H.D. and Shadomy, H.J. (1991) Manual of Clinical Microbiology. $5^{\text {th }}$ ed. American Society for Microbiology, Washington, DC.

10. McDonald, C.L. and Chapin, K. (1995) Rapid identification of Staphylococcus aureus from blood culture bottles by a classic 2 -hour tube coagulase test. J. Clin. Microbiol., 33(1): 50-52.

11. Moreillon, P., Entenza, J.M., Francioli, P., McDevitt, D., Foster, T.J. and Francois, P. (1995) Role of Staphylococcus aureus coagulase and clumping factor in pathogenesis of experimental endocarditis. Infect. Immun., 63(12): 4738-4743.

12. Bello, C.S.S. and Qahtani, A. (2006) Pitfalls in the routine diagnosis of Staphylococcus aureus. Afr. J. Biotechnol., 4(1): 83-86.

13. Cheng, A.G., McAdow, M., Kim, H.K., Bae, T., Missiakas, D.M. and Schneewind, O. (2010) Contribution of coagulases towards Staphylococcus aureus disease and protective immunity. PLoS Pathog., 6(8): e1001036.

14. Yousef, A.E. and Carolyn, C. (2003) Food Microbiology: A Laboratory Manual. John Wiley \& Sons, United States of America.

15. Sperber, W.H. and Tatini, S.R. (1975) Interpretation of the tube coagulase test for identification of Staphylococcus aureus. Appl. Microbiol., 29(4): 502-505.

16. Berke, A. and Tilton, R.C. (1986) Evaluation of rapid coagulase methods for the identification of Staphylococcus aureus. J. Clin. Microbiol., 23(5): 916-919.

17. Makwana, D.G.E., Gadhavi, D.H. and Sinha, D.M. (2012) Comparision of tube coagulase test with mannitol fermentation test for diagnosis of Staphylococcus aureus. Natl. J. Integr. Res. Med., 3(4): 73-75.

18. Varettas, K., Mukerjee, C. and Taylor, P.C. (2005) Anticoagulant carryover may influence clot formation in direct tube coagulase tests from blood cultures. J. Clin. Microbiol., 43(9): 4613-4615.

19. D'Souza, H.A. and Baron, E.J. (2005) BBL CHROMagar Staphylococcus aureus is superior to mannitol salt for detection of Staphylococcus aureus in complex mixed infections. Am. J. Clin. Pathol., 123(6): 806-808.

20. Weckman, B.G. and Catlin, B.W. (1957) Deoxyribonuclease activity of micrococci from clinical sources. J. Bacteriol., 73: 747-753.

21. Anyanwu, N.C.J. and John, W.C. (2013) Conventional and rapid methods for identification of Staphylococcus aureus from clinical specimens. Sci. J. Microbiol., 2(9): 174-178.

22. Murray, P.R., Baron, E.J., Jorgensen, J.H., Pfaller, M.A. and Yolken, R.H. (2003) Manual of Clinical Microbiology. $8^{\text {th }}$ ed. American Society for Microbiology, Washington, DC.

23. Remel Europe Ltd. (2011) Staphaurex ${ }^{\mathrm{TM}}$ Plus Latex Agglutination. Remel Europe Ltd., Dartford, UK.

24. Bhati, T., Nathawat, P., Sharma, S.K., Yadav, R., Bishnoi, J. and Kataria, A.K. (2016) Polymorphism in spa gene of Staphylococcus aureus from bovine subclinical mastitis. Vet. World, 9(4): 421-424. 
25. Akineden, Ö., Annemüller, C., Hassan, A.A., Lämmler, C., Wolter, W. and Zschöck, M. (2001) Toxin genes and other characteristics of Staphylococcus aureus isolates from milk of cows with mastitis. Clin. Diagn. Lab. Immunol., 8(5): 959-964.

26. Indrawattana, N., Sungkhachat, O., Sookrung, N., Chongsa-nguan, M., Tungtrongchitr, A. and Voravuthikunchai, S.P., Kong-Ngoen, T., Kurazono, H. and Chaicumpa, W. (2013) Staphylococcus aureus clinical isolates: Antibiotic susceptibility, molecular characteristics, and ability to form biofilm. BioMed. Res. Int.,
2013: 314654.

27. Kateete, D.P., Kimani, C.N., Katabazi, F.A., Okeng, A., Okee, M.S., Nanteza, A., Joloba, L.M. and Najjuka, C.F. (2010) Identification of Staphylococcus aureus: DNase and mannitol salt agar improve the efficiency of the tube coagulase test. Ann. Clin. Microbiol. Antimicrob., 9: 23.

28. Lagacé-Wiens, P.R.S., Alfa, M.J., Manickam, K. and Karlowsky, J.A. (2007) Thermostable DNase is superior to tube coagulase for direct detection of Staphylococcus aureus in positive blood cultures. J. Clin. Microbiol., 45(10): 3478-3479.

$* * * * * * * *$ 